\title{
ANÁLISE DAS MANIFESTAÇÕES PATOLÓGICAS EM RESERVATÓRIOS ELEVADOS NA CIDADE DE PELOTAS/RS
}

\author{
Analysis of Pathological manifestations in Reservoirs High in the city of Pelotas/RS \\ Ariela da Silva Torres ${ }^{1}$; Vívian Michele Bandeira da Silva ${ }^{2}$, Charlei Marcelo Paliga ${ }^{3}$ \\ Recebido em 26 de setembro de 2015; recebido para revisão em 01 de fevereiro de 2016; aceito em 03 de março de \\ 2016; disponível on-line em 15 de junho de 2016.
}

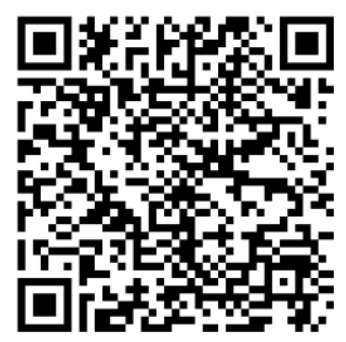

PALAVRAS CHAVE:

Concreto Armado;

Estruturas de

reservatórios;

Patologia em estruturas;

Cobrimento de armadura.

\section{KEYWORDS:}

Reinforced Concrete; reservoir structures; Pathology structures; armor coatings.

\section{* Contato com os autores:}

${ }^{1}$ e-mail: arielatorres@gmail.com (A. da S. Torres)

Enga. Civil, Profa. Dra. do Programa de Pós-Graduação em Arquitetura e Urbanismo da Universidade Federal de Pelotas.

${ }^{2}$ e-mail: vivianbandeira@pelotas.ifsul.edu.br ( V. M. B. da Silva )

Enga. Civil, Esp. em Engenharia Naval, Mestranda do Prog. de Pós-Graduação em Arq. e Urbanismo da Univ. Federal de Pelotas.

${ }^{3}$ e-mail: charleipaliga@gmail.com (C. M. Paliga )

Eng. Civil, Professor Dr. do Departamento de Tecnologia da Construção, Universidade Federal de Pelotas. estações de tratamento através das adutoras ou de reservatórios de maior volume apoiados ou enterrados e distribuí-la até os pontos de consumo. Esta estrutura tem como função principal condicionar e equalizar as pressões nas áreas de cotas topográficas mais altas que não podem ser abastecidas pelo reservatório principal. Este astudo sobre as manifestações patológicas de reservatórios elevados enóstico foi feita através de análise visual com registro fotográfico e após comparação projeto estrutural cedido pelo órgão responsável pelo projeto. Por meio do estudo foi possível identificar manifestações patológicas do tipo: fissuras, sujidade, desplacamentos, corrosão de armaduras e lixiviação. Os resultados das análises das

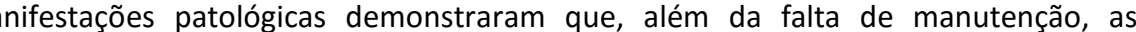
especificações de projeto, referentes aos estribos de pilares e vigas, foram decisivas na propagação da corrosão de armaduras, que estão expostas devido à ocorrência de com os critérios atuais da norma NBR-6118 (ABNT, 2014) público com o estabelecimento de processos adequados de manutenção acelerou a degradação da estrutura e ocasionando assim a falha no funcionamento de abastecimento nos bairros que utilizam estes reservatórios. Desta maneira, este trabalho colaborou para o poder público iniciar o processo de estudo da etapa de manutenção com fim de favorecer a comunidade.

ABSTRACT: Elevated tanks are buildings designed to receive water treatment plants the points of in the areas of highest topographic dimensions that can not be supplied by the main is paper reports a study of the pathological manifestations of elevated tanks was made by visual analysis with photographic record and after comparison with structural design given by the agency responsible for the project. Through the study it 列 of armor and leaching. The results of the analysis of pathological manifestations have shown that in addition to lack of maintenance, design specifications, referring to the of pillars and beams, were instrumental in the spread of corrosion of armor, which are exposed due to the occurrence coatings at odds with the current criteria of -6118 standard (design of reinforced concrete structures). The study concluded that 列 accelerated the degradation of the structure and thus causing a failure in supply operation in the districts using these reservoirs. Thus, this work contributed to the government to start the study process of maintaining these buildings stage in order to promote the community. 


\section{INTRODUÇÃO}

Os primeiros reservatórios que se tem notícia, segundo Kirby et al. (1956), são as cisternas construídas em rochas sãs, desde 25 séculos a.C., por uma civilização que posteriormente tornou-se a comunidade grega. No Brasil, em 1880, segundo Teles (1984) foi inaugurado no Rio de Janeiro, o grande reservatório de Pedregulho, com capacidade para 80 milhões de litros, utilizado para o novo sistema de abastecimento de água da cidade, construído em alvenaria de pedra, com arcadas e tetos abobadados que até hoje causam admiração.

A NBR 12217 (ABNT, 1994) afirma que a função principal de reservatórios elevados é condicionar e equalizar as pressões nas áreas de cotas topográficas mais altas que não podem ser abastecidas pelo reservatório principal da edificação. Portanto reservatórios são construções destinadas a receber a água das estações de tratamento através das adutoras ou de reservatórios de maior volume enterrados ou apoiados e distribuí-la até as edificações.

Segundo Hanai (1981) esta tipologia estrutural pode ser classificada de acordo com três critérios: (1) quanto à finalidade (de acumulação ou de equilíbrio); (2) quanto ao tamanho; (3) e quanto ao sistema construtivo (ser enterrado ou elevado da superfície).

Na cidade de Pelotas, no sul do Estado do Rio Grande do Sul, existem 20 reservatórios distribuídos pela cidade. O primeiro a ser construído foi em 1871 no centro da cidade, conforme pode ser visualizado na Figura 1.
O Reservatório R1 é um monumento de ferro construído com a técnica da pré-fabricação em peças metálicas. Sua planta é em coroa circular, de forma cilíndrica, com a caixa elevada sobre quarenta e cinco colunas. Tem capacidade para $1500 \mathrm{~m}^{3}$ de água. A caixa d'água é um dos quatro bens tombados de Pelotas no Instituto do Patrimônio Histórico e Artístico Nacional (IPHAN), do Ministério da Cultura. O reservatório está registrado no livro de Belas Artes, sob a inscrição no 561, processo 1064-T-82, com data de 19 de julho de 1984.

Com o crescimento da cidade surgiu à necessidade de construção de outros reservatórios e com surgimento de novas tecnologias, foram projetados elementos em concreto armado. $\mathrm{O}$ concreto armado é um material que, sob efeito de intempéries e sem manutenção periódica pode sofrer degradação. Visualizando estes elementos na cidade de Pelotas, estes estão com um alto estágio de degradação, por vários motivos, desde descaso do poder público com manutenção dos mesmos até depredações da própria comunidade onde fica localizado, além da exposição do material que é composto em ação da perda da vida útil.

\section{OBJETIVO}

A partir do quadro exposto, este trabalho propôs uma análise das manifestações patológicas de quatro reservatórios da cidade de Pelotas/RS. 0 material gerado deve auxiliar nas possíveis intervenções de reparação das estruturas estudadas.

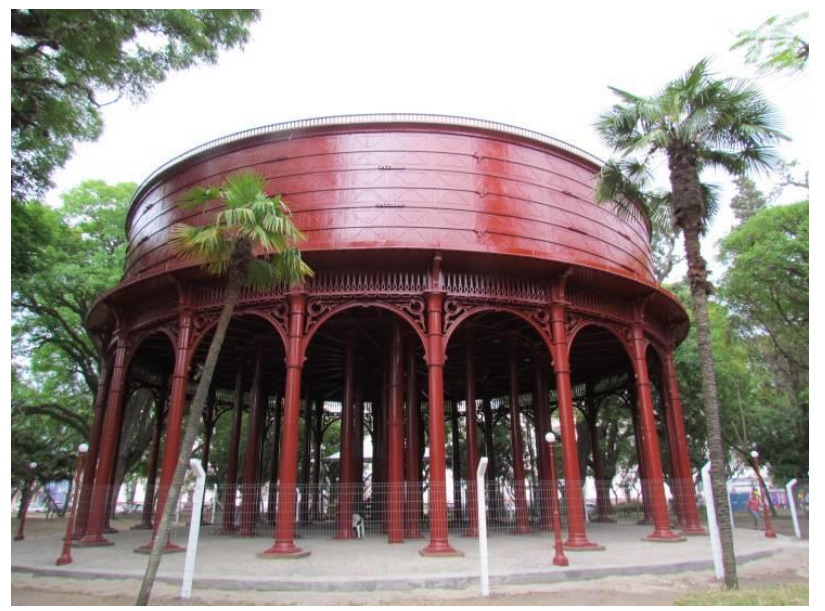

FIGURA 1: Reservatório R1 - primeiro reservatório construído na cidade de Pelotas/RS. 


\section{MANIFESTAÇÕES PATOLÓGICAS}

Nos dias de hoje, em função de diversos fatores, o estudo das manifestações patológicas na construção civil vem se intensificando. Isto se deve ao fato de que até há pouco tempo pensava-se que as estruturas de concreto durariam infinitamente, porém, estudos já comprovaram que isto não é verídico (MATTJE, 2003).

Com o surgimento dos estudos acerca dos problemas que as edificações apresentam ao longo do tempo, Verçoza (1991) descreve, "Patologia, de acordo com os dicionários, é a parte da Medicina que estuda as doenças. As edificações também podem apresentar defeitos comparáveis a doenças: rachaduras, manchas, descolamentos, deformações, rupturas, etc. Por isso convencionouse chamar de Patologia das Edificações ao estudo sistemático desses defeitos".

De acordo com Torres (2011), os processos de manutenção e reparos estruturais na construção civil são motivos de grandes preocupações em função dos elevados gastos gerados. Preocupação esta que é sempre pertinente quando se trata de edificações públicas, onde verbas são escassas e, na maioria das vezes dependentes de muita burocracia, além das construções novas normalmente terem a preferência dos investimentos públicos.

Em uma estrutura, um sintoma, para ser considerado patológico, deve comprometer algumas das exigências de construção, seja de capacidade mecânica, funcional ou estética. Como a manifestação patológica pode ser influenciada pelo comportamento da estrutura em uso, pelo tempo e pelas condições de exposição, percebe-se, portanto, que há uma forte relação entre a manifestação patológica e desempenho, vida útil e durabilidade da edificação (ANDRADE e SILVA, 2005).

Nas construções antigas, a redução natural na resistência dos materiais empregados provoca a deterioração, agravada pela ação agressiva climática. De acordo com Helene (2003), os principais agentes de deterioração são: (1) fatores físicos (variações de temperatura, umidade, calor excessivo, raios ultravioletas, vento, chuva, maresia); (2) fatores químicos (poeira, fuligem, gases poluentes, maresia); (3) fatores biológicos (fungos, insetos, vegetação, bactérias, animais); (4) fatores antrópicos (manuseio, vandalismo, uso inadequado, transportes, processo construtivo inadequado); e (5) fatores naturais (cheias, incêndios, ventos, chuvas, tremores).

\subsection{MANIFESTAÇÕES PATOLÓGICAS EM ESTRUTURAS DE CONCRETO ARMADO}

Tinoco e Morais (2013) inspecionaram 45 reservatórios executados em concreto armado no estado do Rio Grande do Norte entre os anos de 2001 e 2011. Foram observados 39 reservatórios elevados, 5 apoiados e 1 semienterrado. As estruturas avaliadas possuíam idades distintas, pertencem à ambientes de diferentes classes de agressividade e, muitas vezes, foram projetadas em épocas e sistemas construtivos diversos. A metodologia consistiu, essencialmente, em análises visuais, mas em algumas inspeções foram utilizados equipamentos e ensaios tecnológicos. Dentre as estruturas analisadas, 53\% tinham a idade entre 21 e 30 anos na data da vistoria. Tal trabalho identificou as principais manifestações patológicas: 98\% das estruturas apresentaram fissuras, 93\% corrosão de armaduras, 91\% desplacamento do concreto, $64 \%$ vazamento na câmara, 57\% armaduras seccionadas, $39 \%$ manchas e eflorescências, 30\% lixiviação, 16\% segregação do concreto e $14 \%$ deformação na estrutura. Os autores afirmam que os problemas apresentados quase sempre estão relacionados às falhas executivas, ao não atendimento aos projetos e, principalmente, à ausência de manutenção periódica. $\mathrm{O}$ trabalho apresenta percentuais com o tipo de solução adotada para a recuperação das estruturas: $64 \%$ reparo localizado com utilização de graute ou argamassa polimérica tixitrópica, 53\% injeção em fissuras com gel poliuretano bi componente, $22 \%$ demolição total ou parcial, 13\% concreto projetado e $11 \%$ reforço por meio de encamisamento.

O trabalho de Borges (2008) também apresenta as principais manifestações patológicas incidentes em reservatórios de água elevados e executados em concreto armado, mostrando 
medidas preventivas e/ou curativas adotadas para saná-las. A autora escolheu 3 objetos de estudo, localizados no estado da Bahia, dentre 75 casos de reservatórios elevados nos quais uma empresa especializada já havia realizado obras de recuperação. Esta escolha foi definida visando exemplares que apresentassem os problemas mais frequentes entre os reservatórios analisados. De uma maneira geral, a metodologia adotada pela empresa de recuperação contempla as etapas de: vistoria técnica, levantamento de dados, exames/ensaios quando necessário, estudo das soluções e definição da tecnologia adequada para tratamento dos casos e, por fim, definição da equipe, dos materiais e equipamentos a serem utilizados na recuperação. Com a análise de dados referentes às manifestações patológicas apresentadas, constatou-se que a percolação e/ou infiltração de água, corrosão de armaduras e fissuras foram os problemas mais frequentes nesses reservatórios.

\section{METODOLOGIA}

Para alcançar os objetivos deste estudo, além da pesquisa bibliográfica, que procura explicar um problema a partir do registro disponível, utilizando-se de referenciais teóricos já trabalhados e devidamente publicados por outros pesquisadores (SEVERINO, 2007), empregou-se também, o estudo de caso, utilizado quando se deseja entender um fenômeno da vida real em profundidade, sendo que este entendimento engloba importantes condições contextuais (YIN, 2010).

A análise do objeto de estudo foi feita por meio do método mapa de danos, que de acordo com Barthel et al. (2009 apud Pereira, 2012) é definido como além de uma representação gráfica das manifestações patológicas existentes em uma edificação, um registro da evolução do estado de conservação da mesma, uma vez que a análise tenha sido efetuada, em certo momento, servirá de base para futuras análises contra o avanço de patologias detectadas na edificação.
A metodologia, portanto, deste estudo baseou-se em vistoria do local, com levantamento visual e fotográfico dos reservatórios estudados e, posteriormente, a análise dos projetos que foram cedidos pelo órgão público de saneamento da água da cidade. Estas etapas de vistoria e anamnese geraram subsídios suficientes para o diagnóstico das manifestações patológicas, com identificação das possíveis causas e origens, bem como, sugestões de reparo e/ou conservação.

Os quatro reservatórios analisados foram: R10 T, R5 T, R7 T e R8 T, todos construídos em meados da década de 80 , em concreto armado. Salienta-se que o R $10 \mathrm{~T}$ teve um estudo mais aprofundado em função de ser o que possui o maior avanço de degradação do concreto armado e também de ter sido o único que os projetos foram fornecidos.

O R10 T possui capacidade média de $1000 \mathrm{~m}^{3}$, uma estrutura com diâmetro de 17,0 m e altura de $23,0 \mathrm{~m}$. Este reservatório possui como vizinhança um campo para atividades esportivas e uma praça em estado precário em função de falta de manutenção, porém, mesmo assim é bastante utilizada por moradores da região. O reservatório e sua vizinhança também são muito frequentados por moradores de rua e usuários de drogas, tornando o local totalmente vulnerável a vandalismos e crimes.

Colaboradores do SANEP (Serviço Autônomo de Saneamento de Pelotas) informaram que o projeto foi concebido pela própria instituição. O processo construtivo iniciou em abril de 1986 com estudo do solo e no ano de 1987 começou a construção. Em setembro de 1987 a empresa aplicou reboco nas paredes internas e pintura a base de borracha clorada como elemento impermeabilizante, liberando seu uso após 10 dias deste procedimento, sem realizar os testes de cargas previamente indicados. A referida obra foi utilizada em um período muito pequeno, ficando em desuso e sem intervenções de manutenção em todos seus anos de existência.

0 reservatório $\mathrm{R} 5 \mathrm{~T}$ tem capacidade de $500 \mathrm{~m}^{3}$, foi construída no ano de 1958 e está localizada na Rua 
Frontino Vieira no Bairro Fragata, sendo sua zona de abastecimento o bairro citado. O R8 T abrange os Bairros Areal e os Balneários da cidade, tem capacidade de $2000 \mathrm{~m}^{3}$, foi construído no ano de 1979 e está localizado na Rua Professor Mario Peiruque na Vila Bom Jesus. O reservatório R7 T, localiza-se na Rua Machado de Assis na Vila Gotuzzo, possui capacidade de $500 \mathrm{~m}^{3}$ e foi construído no ano de 1985, 27 anos após o R5 T, mas possui características de projeto semelhantes, sendo destinado à mesma zona de abastecimento. Os reservatórios R5 T, R7 T e R8 T podem ser visualizados na Figura 2.

\section{RESULTADOS E DISCUSSÕES}

A partir da metodologia exposta, os resultados serão apresentados em duas etapas: (1) etapa de levantamento fotográfico, e posterior (2) análise dos dados com sugestões de possíveis reparos.

\subsection{DIAGNÓSTICO: ETAPA DE LEVANTAMENTO FOTOGRÁFICO}

A primeira etapa de diagnostico com levantamento visual e fotográfico foi feito no $\mathrm{R} 10$

T. O registro iniciou sobre as vigas, lajes e paredes superiores conforme Figura 3. A figura apresenta um detalhe das vigas $e$ pilares, tendo uma visão da parte inferior e lateral respectivamente. Nota-se, em ambos os elementos estruturais, um processo de degradação avançado, onde já ouve descolamento do cobrimento de concreto e exposição da armadura que, visualmente, já pode ser identificada com processo corrosivo.

De acordo com Guimarães (1995) o cobrimento das armaduras é a proteção que deve ser executada cuidadosamente, pois PE através da abertura de fissuras nesta região que os agentes agressivos do meio ambiente agem sobre o concreto e sobre a armadura, provocando, respectivamente, os processos de deterioração e corrosão. O cobrimento representa a menor distância entre qualquer das faces da peça e a superfície da barra, fio, cordoalha ou bainha metálica considerada, inclusive estribos e barras de montagem.

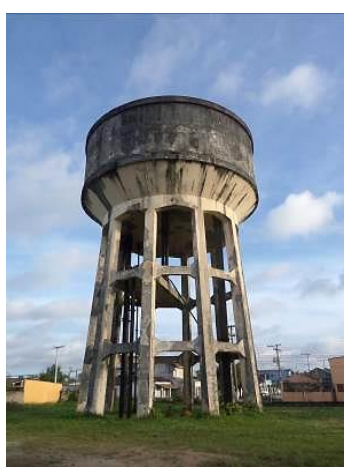

(a)

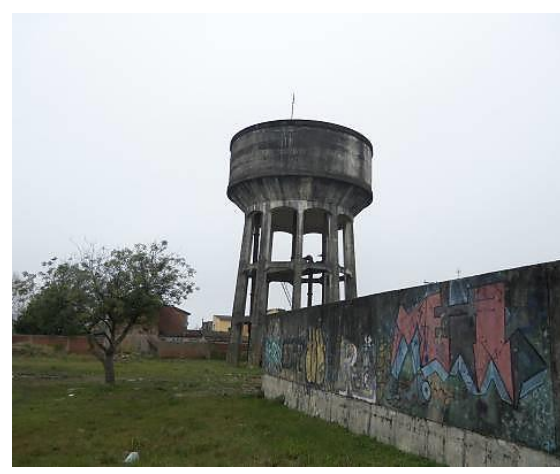

(b)

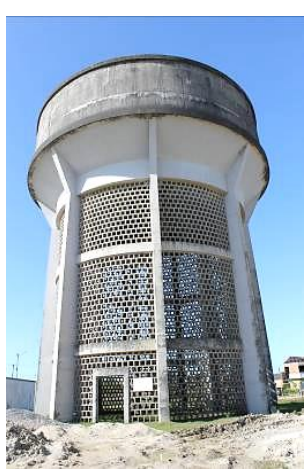

(c)

FIGURA 2: Reservatórios: (a) R5 T; (b) R7 T; (c) R8 T. FONTE: AUTORA - 2014

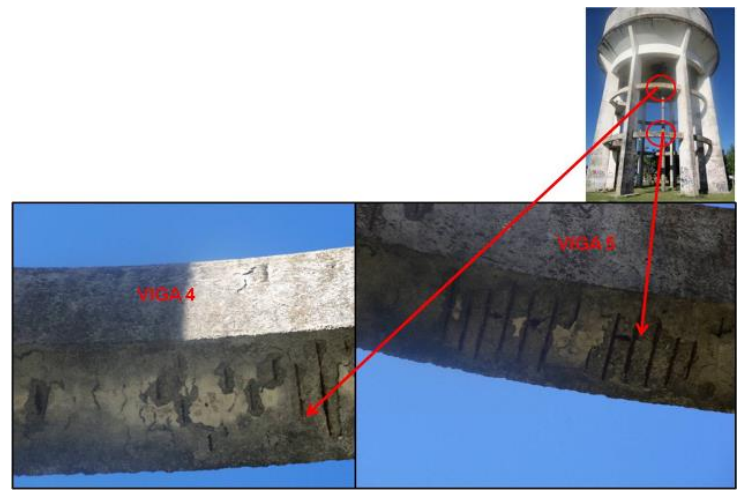

(a)

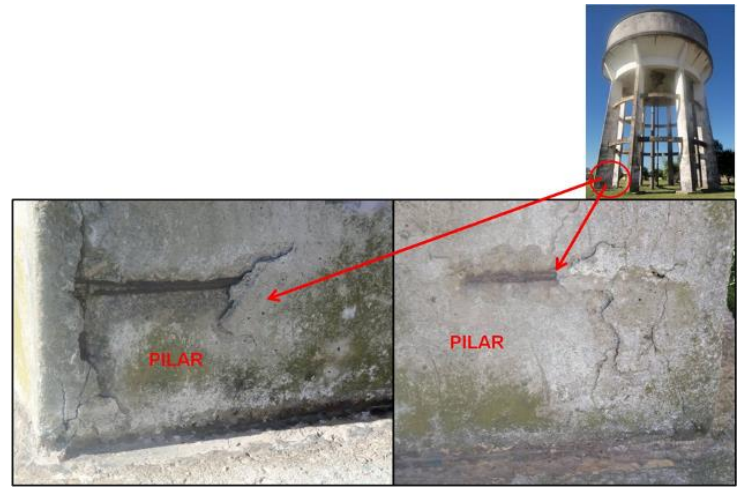

(b)

FIGURA 3: R10 T - Manifestações patológicas: (a) nas vigas 4 e 5; (b) nos pilares. FONTE: AUTORA - 2014. 
A Figura 4 expõem os problemas encontrados nos pilares do reservatório em estudo, observa-se ocorrência de fissuras e principalmente a ação de vandalismos no elemento, onde aparecem pichações e até mesmo resto do que foi local de usuários de drogas, que tornaram o reservatório em espaço para queimas de mercadorias.

$\mathrm{Na}$ Figura 5 está o registro das lajes do R10 T, nas imagens é possível notar a ação da

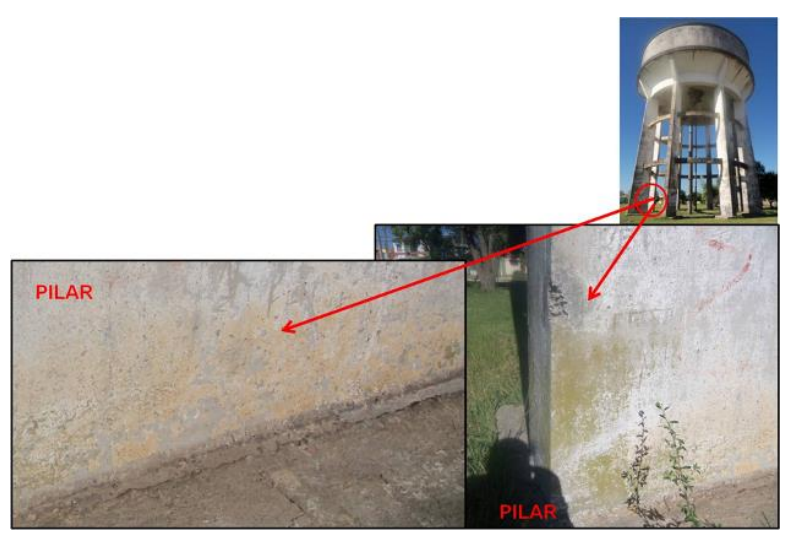

(a) corrosão, com já perda da camada de cobrimento e exposição das armaduras com já perda de seção.

A Figura 6 apresenta o reservatório R5 T que está em funcionamento, mas possui graves problemas de vazamentos devidos a trincas existentes, o que acarreta em um grande desperdício de água que deveria estar chegando limpa nas residências. A imagem mostra também grande efeito da sujidade e desplacamento das camadas de revestimento.

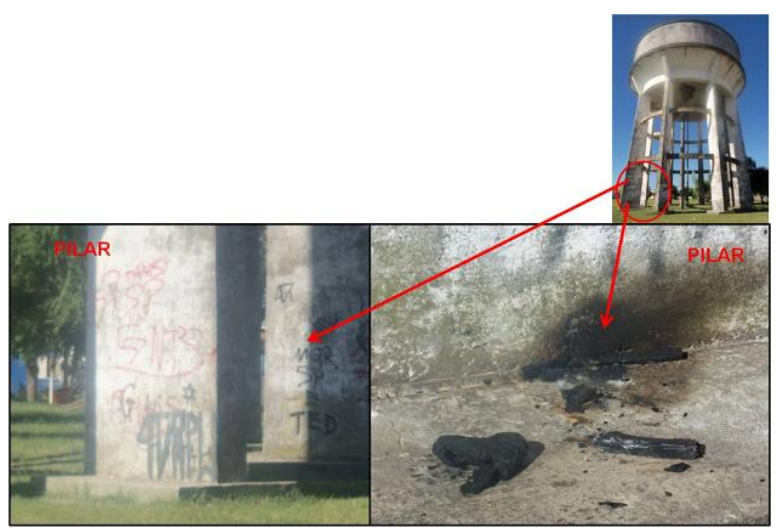

(b)

FIGURA 4: R10 T - Manifestações patológicas nos pilares: (a) fissuração; (b) ação de vandalismo. FONTE: AUTORA - 2014

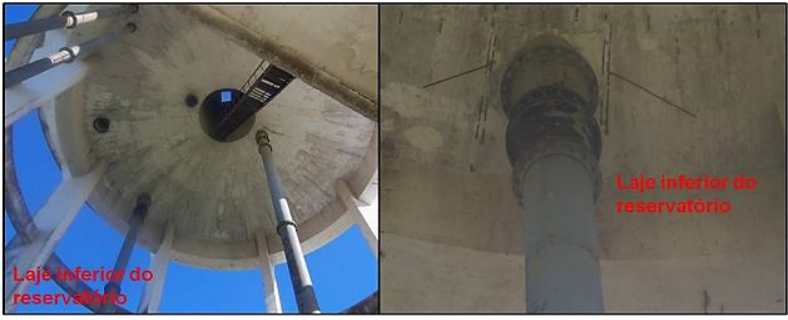

(a)

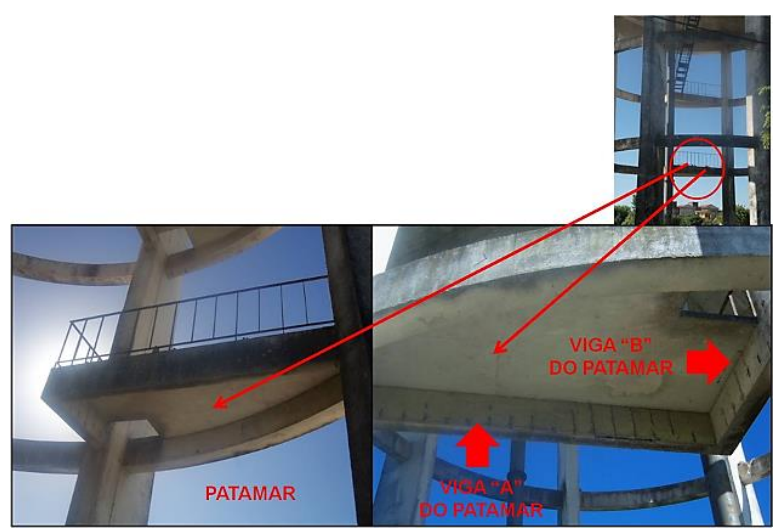

(b)

FIGURA 5: R10 T - Manifestações patológicas nas lajes: (a) laje inferior; (b) patamar.

FONTE: AUTORA - 2014.

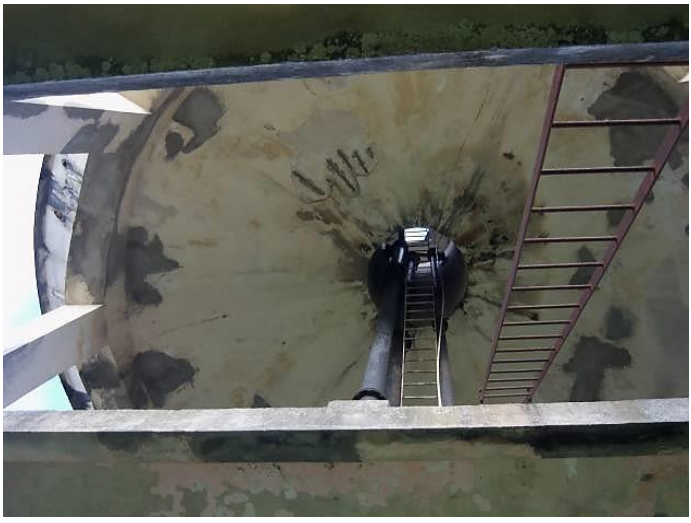

(a)

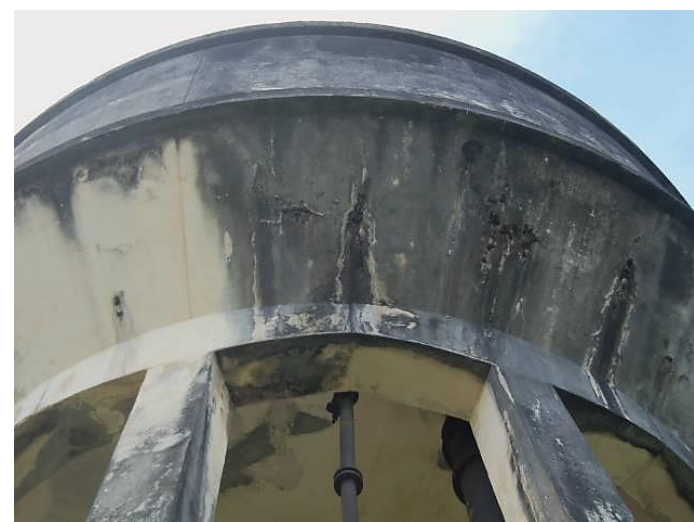

(b)

FIGURA 6: R5 T - Imagens do reservatório Bairro Fragata: (a) laje inferior; (b) vista lateral. FONTE: AUTORA - 2014. 
O terceiro reservatório analisado foi $R 8 \mathrm{~T}$, obtendo-se as imagens da Figura 7 que mostram algumas manifestações patológicas. Nota-se as imagens a total perda da camada de cobrimento e total exposição das barras e mais uma vez perda de seção transversal das armaduras. Esta perda de resistência mecânica do reservatório é um possível risco as pessoas que se aproximarem do local.

O quarto reservatório aparece nas imagens da Figura 8, possui danos visíveis relacionados à falta de manutenção e ausência de elementos de proteção contra vandalismos.

\subsection{ANÁLISE DOS FOTOGRÁFICOS}

A Tabela 1 compila os resultados obtidos na analise dos reservatórios, informando danos como: manchas, sujidades e corrosão de armaduras expostas, apresentando as possíveis causas e sugerindo técnicas de reparo e/ou conservação. Porém é importante salientar que inúmeras manifestações patológicas que estão presentes nos reservatórios têm origem em falta de manutenção periódica nestes elementos que acabam acarretando desperdício de água e um gravíssimo dano a população que necessita para sua sobrevivência.

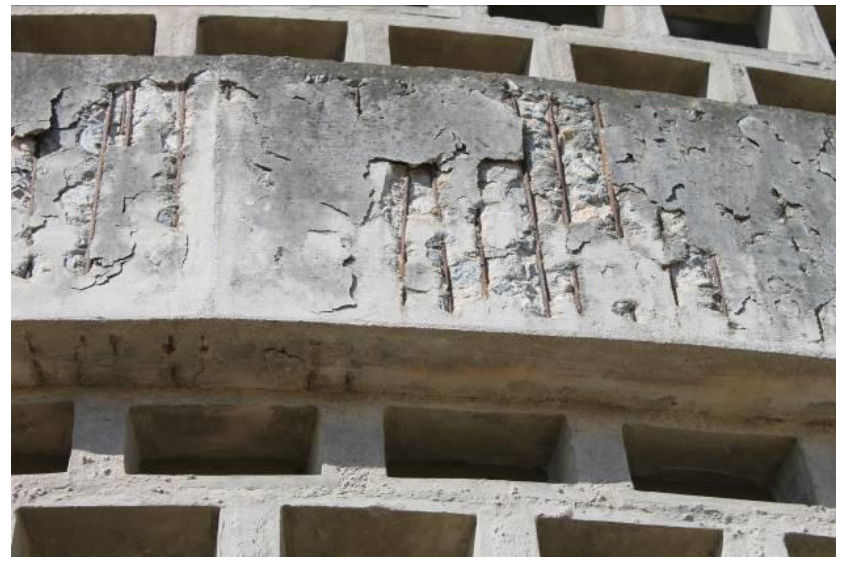

(a)

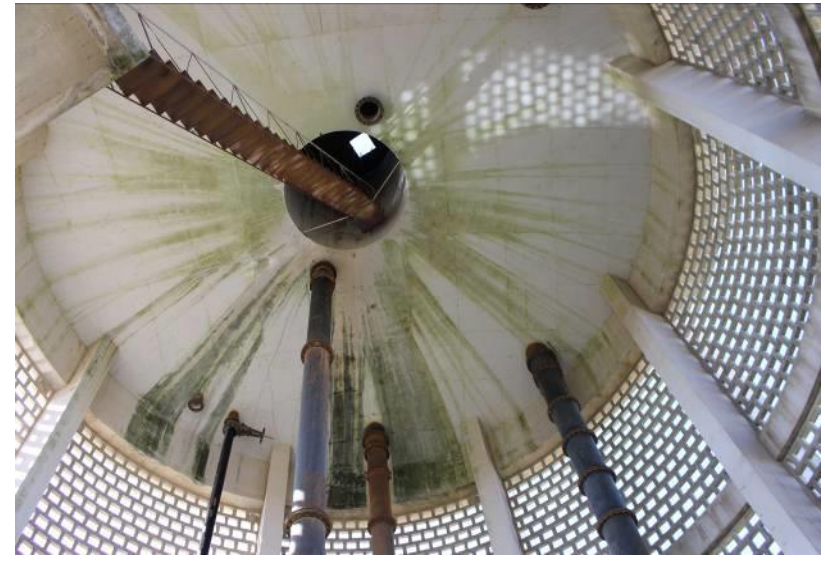

(b)

FIGURA 7: R8 T - Imagens do reservatório Bairro Vila Bom Jesus: (a) laje inferior; (b) vista lateral. FONTE: AUTORA - 2014.

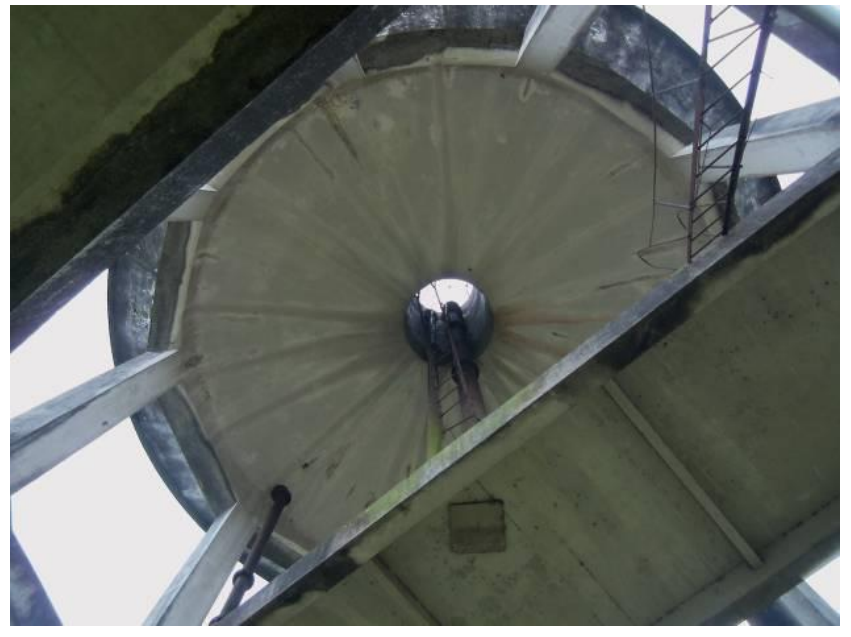

(a)

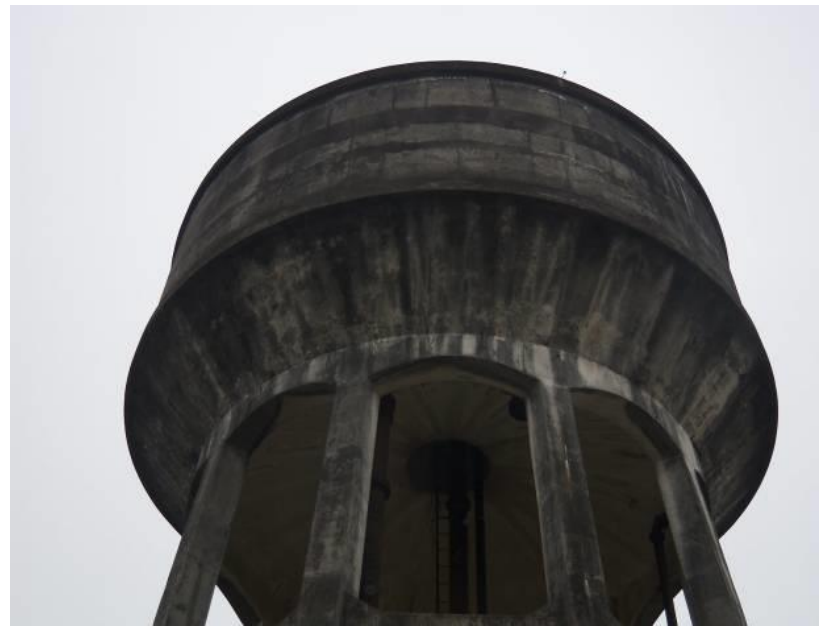

(b)

FIGURA 8: R7 T - Imagens do reservatório Bairro da Vila Gotuzzo: (a) laje inferior; (b) vista lateral. FONTE: AUTORA - 2014. 
TABELA 1: Análise das manifestações patológicas encontradas nos reservatórios.

\begin{tabular}{|c|c|}
\hline $\begin{array}{c}\text { Manifestação } \\
\text { patológica }\end{array}$ & Causas prováveis \\
\hline $\begin{array}{l}\text { Manchas e } \\
\text { sujidades. }\end{array}$ & $\begin{array}{l}\text { As vigas não possuem } \\
\text { pingadeiras; } \\
\text { As partes superiores das } \\
\text { vigas são retas, retém a } \\
\text { umidade da água da } \\
\text { chuva; ausência de um } \\
\text { plano de manutenção. }\end{array}$ \\
\hline $\begin{array}{l}\text { Armaduras } \\
\text { expostas com } \\
\text { corrosão. }\end{array}$ & Cobrimento insuficiente \\
\hline
\end{tabular}

Reparo / Conservação

Construção de superfície inclinada na parte superior das vigas e de pingadeiras.

Fissuras, lascamentos, desagregações e armaduras expostas com corrosão.
Falha de projeto: cobrimento da armadura não obedece a norma; Falha de execução: não utilização de espaçadores para garantir o cobrimento.
Remoção do concreto danificado e contaminado ao redor da armadura corroída; Limpeza rigorosa no aço;

Avaliação da perda de área de aço;

Tratamento anticorrosivo na armadura;

Aplicação de produto com função de aderência;

Aplicação de graute para reparo;

Pintura de acabamento.

Remoção do concreto danificado e contaminado ao redor da armadura corroída; Limpeza rigorosa no aço; Avaliação da perda de área de aço; Tratamento anticorrosivo na armadura;

Aplicação de produto com função de aderência;

Aplicação de graute para reparo;

Pintura de acabamento. Escovação e limpeza;

Pintura de acabamento; Construção de grade de proteção ao redor do reservatório para evitar entrada de animais e pessoas;

Manter a vegetação cortada.

\begin{tabular}{ccc}
\hline Pichações, & Queimas que ocorrem & Escovação e limpeza; \\
degradação e & junto à estrutura, devido & Pintura de acabamento; \\
aumento de & ao acesso de vândalos e & Construção de grade de \\
tensão nos & usuários de drogas. & proteção ao redor do \\
materiais. & & $\begin{array}{c}\text { reservatório para evitar } \\
\text { entrada de vândalos e } \\
\end{array}$ \\
& usuários de drogas. \\
\hline
\end{tabular}


A partir de uma análise das observações obtidas nas vistorias dos locais foi possível realizar uma observação quanto aos cobrimentos do concreto definidos em projetos, nos cobrimentos realmente executados e nos cobrimentos sugeridos pela norma NBR 6118 (ABNT, 1980), década da realização dos projetos, e da NBR 6118 vigente na atualidade.

As vigas 4 e 5, identificadas na Figura 3, foram alvo deste estudo demonstrado na Tabela 2. Sendo o cobrimento, sugerido pela norma NBR 6118 (ABNT, 1980), para concreto aparente ao ar livre e na NBR 6118 (ABNT, 2014) para pilar e viga de concreto armado em classe de agressividade 2 moderada.

Observa-se que a especificação intencionada no projeto $(1,5 \mathrm{~cm})$ não obedecia a norma vigente na época da construção e verificando-se que o cobrimento real $(0,87 \mathrm{~cm})$ ficou ainda menor que as designações de projeto devido ao fato de, no desenho de estribo, não ser

TABELA 2: Comparativo dos cobrimentos de concreto para vigas.

Comparativo Cobrimento $(\mathrm{cm})$

NBR 6118 (ABNT, 1980)

2,5

NBR 6118 (ABNT, 2007)

3,0

NBR 6118 (ABNT, 2007)

3,0

Intencionado no projeto diâmetro $(0,64 \mathrm{~cm} \times 2=1,28 \mathrm{~cm})$ observados em análise dos projetos no SANEP. Registrando-se que a atual NBR 6118 (ABNT, 2007) recomenda o cobrimento mínimo de $3 \mathrm{~cm}$ para vigas, sendo que este acréscimo proporciona maior proteção da armadura. dos valores de cobrimento para os pilares, conforme Tabela 3. Observa-se que a especificação intencionada no projeto $(2,5 \mathrm{~cm})$ obedecia a norma vigente na época da construção; porém, verifica-se que o cobrimento real $(1,87 \mathrm{~cm})$ é menor que a designação de projeto devido ao fato de, no desenho dos estribos, não ser considerado o acréscimo de duas vezes a medida do diâmetro dos mesmos $(0,64 \mathrm{~cm} \times 2=1,28 \mathrm{~cm})$. Verificando-se que a NBR 6118 (ABNT, 2007) recomenda o cobrimento mínimo de $3 \mathrm{~cm}$ para pilares, alteração que visa a prevenção de manifestações patológicas no concreto armado.

TABELA 3: Comparativo dos cobrimentos de concreto para pilares.

Comparativo

NBR 6118 (ABNT, 1980)

2,5

considerado o acréscimo de duas vezes a medida do

Novamente foi realizado um comparativo

Cobrimento $(\mathrm{cm})$

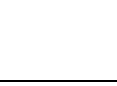


A partir das analises realizadas, verificouse a ausência do comprimento de cobrimento mínimo indicado pelas normas vigentes na época de projeto e execução dos projetos e acredita-se que este equívoco tenha sido fundamental para aparecimento das manifestações patológicas nos elementos estudados.

\section{CONCLUSÕES}

Os resultados das análises das manifestações patológicas demonstraram que, além da falta de manutenção, as especificações de projeto, referentes aos estribos de pilares e vigas, foram decisivas no surgimento da corrosão de armaduras, que estão expostas devido à ocorrência de cobrimentos discordantes com a norma. Para o projeto e execução de armaduras transversais é necessário considerar que as medidas de desenvolvimento estabelecidas pelas cotas do projeto terão acréscimo de duas vezes o diâmetro do aço, aumentando a largura e altura do estribo; caso este fato não seja considerado no desenho de desenvolvimento da armadura, o cobrimento real de concreto será inferior ao desejado.

É possível concluir que para pleno funcionamento do reservatório R10 $T$ faz-se necessário a construção de um reservatório semi enterrado para possibilitar o bombeamento para o elevado. Este outro reservatório não foi executado na época da construção por falta de recursos financeiros. Os outros reservatórios precisam urgentemente um plano de reforma e posterior um plano de manutenção.

Este estudo fornece subsídios necessários para o início do processo de intervenção nestas estruturas, auxiliando na economia deste processo, visto que as manutenções poderão ser pontuais nas manifestações patológicas. Também servirá de base para continuidade deste grande projeto a fim de avaliar todos os reservatórios existentes na cidade de Pelotas/RS.

\section{REFERÊNCIAS BIBLIOGRÁFICAS}

ANDRADE, T.; SILVA, A. J. C. Patologia das Estruturas. In: ISAIA, Geraldo Cechella (Ed.). Concreto: ensino, pesquisa e realizações. São Paulo: IBRACON, 2005. 2v. Cap.32 p.953-983.

ASSOCIAÇÃO BRASILEIRA DE NORMAS TÉCNICAS. Projeto e Execução de obras de concreto Armado Procedimento. NBR 6118. Rio de Janeiro, 2014.

ASSOCIAÇÃO BRASILEIRA DE NORMAS TÉCNICAS. Projeto e Execução de obras de concreto Armado Procedimento. NBR 6118. Rio de Janeiro, 2007.

ASSOCIAÇÃO BRASILEIRA DE NORMAS TÉCNICAS. Projeto e Execução de obras de concreto Armado Procedimento. NBR 6118. Rio de Janeiro, 1980.

ASSOCIAÇÃO BRASILEIRA DE NORMAS TÉCNICAS. Projetos de reservatório de distribuição de água para abastecimento público. NBR 12217. Rio de Janeiro, 1994.

BARTHEL, C.; LINS, M.; PESTANA, F. O papel de danos na conservação do patrimônio arquitetônico. In: Congresso Iberoamericano y VIII Jornada "Tecnincas de Restauracion e Conservacion Del Patrimonio", 2009. La Plata, Buenos Aires, Argentina. $20 \mathrm{p}$

BORGES, M. G. Manifestações patológicas incidentes em reservatórios de água elevados executados em concreto armado. Monografia. Universidade Estadual de Feira de Santana - UEFS. Feira de Santana, 2008.

GUIMARÃES, A.E.P. Indicações para projeto e execução de reservatórios cilíndricos em concreto armado. Dissertação de mestrado. Escola de Engenharia de São Carlos - Universidade de São Paulo, 1995.

HANAI, J.B. Reservatórios com parede ondulada. São Carlos. Dissertação (Mestrado) - Escola de Engenharia de São Carlos, Universidade de São Paulo, 1981.

HELENE, P.R.L. Manual de reparo, proteção e reforço de estruturas de concreto. São Paulo: Pini, 2003.

KIRBY, R.S. ET AL. Engineering in history. New York, McGraw-Hill, 1956.

MATTJE, A. Contribuição ao estudo da durabilidade de pontes em concreto do Sistema Rodoviário de Santa Catarina (Litoral e Vale do Itajaí). Dissertação de mestrado em Engenharia Civil. Universidade Federal de Santa Catarina, Florianópolis, 2003. 
PEREIRA, Luciana M. Avaliação das Patologias e da Biodeterioração na Biblioteca Central da UFSM. 2012. 126f. Dissertação (Mestrado em Engenharia Civil e Ambiental)- Programa de Pós-Graduação em Engenharia Civil e Ambiental. Universidade Federal de Santa Maria, Santa Maria.

SEVERINO, Antônio J. Metodologia do Trabalho Científico. 23 ed. rev. e atual. São Paulo: Cortez, 2007.

TELES, P.C.S. Historia da engenharia no Brasil (século XVI a XIX). São Paulo, Livros Técnicos e Científicos, 2v. 1984.

TORRES, A. S. Corrosão por cloretos em estruturas de concreto armado: Uma meta- análise. Tese de doutorado em Engenharia Civil. Universidade Federal do Rio Grande do Sul, Porto Alegre, 2011.

VERÇOZA, E. J. Patologia das Edificações. Porto Alegre, Editora Sagra, 1991. 172p.

YIN, Robert K. Estudo de Caso: Planejamento e Métodos. 4o ed. Porto Alegre: Bookman, 2010.

Tinoco, H. F. F., Morais, A. S. Reservatórios em concreto armado: principais manifestações patológicas, diagnóstico e soluções para reabilitação e reforço. IX Congresso Internacional sobre Patologia e Recuperação de Estruturas - CINPAR. João Pessoa, 2013. 